\title{
Nursing in Occupational Health
}

\section{MARY LOUISE BROWN, R.N.}

$\mathrm{T}$ HE KEY to occupational health nursing is the environment in which it is practiced. The mere fact that the occupational health nurse practices her profession not in the hospital, not at the bedside, but at the work place opens up a new and broad vista of service and offers an incomparable challenge to her professional capabilities.

The people to whom the occupational health nurse gives service are not traditional "patients" but workers. The care at times is curative, at other times, rehabilitative. Increasingly, in modern programs it is preventive, as the nurse participates in health maintenance and health promotion activities.

In 1895 the first industrial nurse in the United States assumed her duties. The president of the Vermont Marble Company, motivated by his own concern for employee welfare, influenced his board of directors to employ a "district" nurse. Ada Mayo Stewart was engaged to work among the employees of the company. Her work was that of a visiting nurse. She went into the homes of the workers to give care to the sick and into the schools to teach health to children (1).

In 1897 the Benefit Association of the John Wanamaker Company of New York City employed a nurse. She gave first aid, arranged for medical care, and made followup visits to insure that the doctor's orders were understood and followed. She distributed the financial as-

Miss Brown is chief, Occupational Health Nursing Section, Division of Occupational Health, Public Health Service. sistance which the benefit fund provided for its members. By 1900 there were 21 companies known to have employed nurses (1).

The first major growth period for occupational health nursing was between the years 1914 and 1930, when 47 States enacted workmen's compensation laws (2). This social legislation provided the incentive for accident prevention and inplant care to workers with industrial injuries. During these years increased production for World War I greatly influenced the growth of occupational health nursing. Nurses were employed to staff first aid rooms in heavy manufacturing industries and shipyards.

The early industrial nurse sometimes found that foremen did not realize the benefits of immediate care for minor injuries and objected to workers leaving their jobs to report to the nurse. The worker, accustomed to applying his own first aid, sometimes objected to being sent to the nurse. Workers, skillful in removing foreign bodies from a fellow worker's eyes, often were critical of the nurse's techniques. Despite their difficulties, these first industrial nurses established once and for all that the nurse has a place in industry.

The period from 1930 to 1946 includes important milestones for occupational health nursing brought about by depression, social security legislation, and World War II.

Many occupational health nurses lost their jobs in the 1930's because the country was in the midst of a serious economic depression. Those who were retained found that workers were seeking help with family-related health and welfare problems. Workers did not have 
unemployment compensation insurance nor medical and hospital care insurance, as so many do today. It was during this period that health counseling and health education became an accepted role for the occupational health nurse, just as care for industrial injuries can be traced back to the influence of workmen's compensation insurance.

The Social Security Act of 1935 made Federal funds available to the Public Health Service for grants-in-aid to the States for public health work, including industrial hygiene. These grants stimulated the development of State industrial hygiene units. Before 1936 there were only seven industrial hygiene divisions in six States, and one city health department. By the mid-1940's there were some 47 units operating in 38 States, 7 cities, and 2 counties (3). The first industrial nursing consultant was employed in 1939 by the Indiana State Board of Health, and in 1940 Michigan added a similar position to its staff.

In 1941 the Division of Industrial Hygiene of the Public Health Service was asked to guide the development of industrial health programs in defense industries (4). Because nursing was an essential part of these programs, a full-time nursing consultant, Olive Whitlock, was assigned to the division, where she worked closely with physicians, engineers, and chemists in planning nursing as part of the complete industrial hygiene program. Miss Whitlock gave leadership to the first nationwide survey of duties of nurses in industry.

In 1940 the public health nursing section of the American Public Health Association appointed a committee to study duties of nurses in industry. Before this survey got underway, industry was in the midst of expansion from peacetime to wartime production, and the number of nurses employed in industry increased from 5,512 in 1941 to about 10,000 at the end of 1942, and 11,200 in 1943.

The Division of Industrial Hygiene, through Miss Whitlock, collaborated with the APHA committee to obtain factual information on industrial nursing practices in the country. The report of their survey (5) served as a basis for determining the range of industrial nursing practices, defining current problems, and formulating standards of practice.
During World War II it became increasingly important to think in terms of conserving the health of the worker. Many women were employed by the heavy manufacturing industries, and handicapped and older workers were drawn in large numbers into the labor force. Industrial health services gave more attention to preventive measures designed to maintain the health and productivity of the workers.

In the cold-war years that have followed World War II, women have continued to be a substantial part of the labor force. The advancing age level of the working population and the rising incidence of chronic and degenerative diseases have increased the need for early detection and prevention of all diseases, not only those related to the occupations. The importance of conserving the total health of the worker continues to gain recognition in industry. Many companies now require periodic health examinations. Workers, too, are health conscious and participate in immunization programs and mass screenings to detect disease.

Health education and counseling are being increasingly recognized as essential components of effective health maintenance programs in industry. Moreover, the role of the able occupational health nurse in this area is taking on new importance with the growing recognition of psychological factors in illness. Her need for special preparation in this area is obvious. The mental health disorders are of sufficient magnitude to pose a serious problem to industry in terms of employee health efficiency. Some of the larger occupational health programs already include psychiatrists as members of the staff, and industrial mental health programs are beginning to be developed. Effective handling of workers' reactions to stress will in large part depend on the ability of the occupational health nurse to recognize worker needs and to plan for and to give care. A precedent for this enlarging role exists.

Mental health has long been accepted as a part of public health programs, and the nurse plays an important part in recognizing the emotionally disturbed child and adult and planning for care. In a modern occupational health program, the occupational health nurse can perform a similar function for employed adults. Health evaluation and counseling of 
emotionally disturbed workers are today's challenges to occupational health nurses.

The effect of two world wars, the depression of the 1930's, the Social Security Act, and workmen's compensation legislation are forces that have influenced the character of industrial health programs and thereby changed the character of occupational health nursing practice.

Industry's concern for workers with compensable injuries provided the foundation on which broader programs of worker health maintenance have been built. However, the transition from the accident prevention period to the adult health maintenance phase is still only a trend. In many instances occupational health nursing has not achieved its potential because it has been held fast in the bedrock concept of emergency care. The true role of the occupational health nurse was visualized in 1923 by the Committee for the Study of Public Health Nursing Education (Josephine Goldmark, secretary). In the now famous Goldmark report (6), the chairman, C.-E. A. Winslow, said:

Clearly, if industrial medicine and nursing were organized on the proper scale and had the personnel adequate to reach these individuals effectively for the care of their health, for protection against occupational hazards and diseases, and for the teaching of good hygienic habits, the health of the nation would soon be appreciably affected.

The individuals referred to in the 1920's were the 15 million men and women in the labor force. In 1964 there are 73 million workers. Occupational health nursing has made much progress, but it has never reached its potential for improving the health of the nation.

If occupational health nursing is ever to have a significant impact on the health of the nation, the nurse in industry, her employer, the physician, and the employees as well must come to recognize that the role of the occupational health nurse includes all of the following:

1. Giving expert nursing care to injured and ill workers.

2. Advising and helping workers use community health and welfare resources for their own and their families' needs.

3. Teaching and motivating employees to be safety and health minded.
4. Participating in health evaluation programs.

5. Keeping the health unit and themselves ready to handle any emergency, large or small.

6 . Knowing the inherent hazards associated with the industry products or services, and the signs and symptoms of the acute and chronic reactions to them.

7. Understanding the interdependence of the contribution of labor and management to the free enterprise system of American business.

Two factors have been the principal limiting influence in occupational health nursing. One is isolation and the other is lack of education and training available in this field. Unfortunately, these two factors create a vicious circle. The isolation of occupational health nurses inhibits stimulus and development of training and, without adequate preparation for their role, nurses cannot free themselves from the isolation imposed on them by circumstance.

Approximately two-thirds of all occupational health nurse positions are in establishments too small to justify a full complement of staff. All too often the occupational health nurse has been educated for work in a hospital. The part-time doctor with whom she works is often a general practitioner with a limited knowledge of occupational medicine. And the industrial management person who employs her has no real concept of what role the nurse can and should play.

This is not to say that individual occupational health nurses, part-time physicians, and industrial management people have not created excellent occupational health programs. It is from the experience of creative and dedicated people working within such limitations that the true potential of occupational health has been visualized. Too often, however, the occupational health nurse, working alone and without regular contact with her colleagues, has been unable to recognize the full potential of her profession.

The isolation of the occupational health nurse has another aspect. Her relationship with community nursing agencies has not always been one of mutual support. Often the direct opposite has been true, despite the natural alliance between occupational and community health recognized by public health leaders from Winslow's time to the present day. Seldom are the 
services of public health agencies made available to workers through the place of employment.

Furthermore, lack of communication exists between the occupational health nurse and the hospital. At a time when continuity of patient care is the watchword of the profession, the occupational health nurse's record is seldom included in referrals. Indeed, a patient may go from industry to the hospital, from the hospital to his home, and back to work without the occupational health nurse being involved with the public health nurse or any other person in planning care.

The occupational health nurse must herself bear a part of the blame for this lack of cooperation. The nurse in industry needs a thorough understanding of her role if she is to bridge the gap which separates her from her colleagues in the community.

In addition to its immediate and direct effect upon the individual nurse, isolation has inhibited the development of training. The need for special training for the occupational health nursing specialty has long been recognized. In 1915 nurses working in industry in the Boston area took note of the problems faced by nurses who were hospital oriented but who were now working in factory and shipyard emergency rooms. In 1916, through their efforts and that of the women's division of the National Civic Federation, a 16-week course in industrial service for nurses was given in weekly 2 -hour evening sessions. This course was repeated annually for the next 5 years by the college of business administration of Boston University ( $(y)$. Unfortunately, this early training effort did not create a trend for concerted action. The 1923 Goldmark report ( 6 ) pointed out the need:

In justice to the nurse herself in view of her prospective responsibilities, in justice to those whose welfare is entrusted to her, in justice above all to the community which pays in deteriorated manhood and womanhood for the unrepaired injuries of industry, the industrial nurse needs a sound and rounded training.

In the 41 years since the Goldmark report was published, "sound and rounded" training for the nurse who works in industry has not been available to occupational health nurses except briefly in the post-World War II years, when several schools of nursing offered special courses in industrial nursing. These programs were not oversubscribed and, as nursing education patterns changed in the 1950's to nonspecialization on a baccalaureate level, they were discontinued.

Two graduate-level programs were established, one in 1950 and the other in 1959. These were not widely accepted, and in 1964 none are in operation. Why has this happened when such programs have expanded in all other areas of nursing? Isolation and the resulting lack of leadership provide the clue.

An enlightening contrast can be seen in the development of training for public health nurses. Nurse supervisors and administrators in public health agencies recognized early the need and stimulated the demand for specialized training. Working as part of a staff under the supervision of a nurse administrator or nurse supervisor, the public health nurse was urged to seek special preparation for her field, first in certified courses and then at the baccalaureate level.

On the other hand, if an occupational health nurse sought to learn about the development of occupational health nursing programs, industrial hygiene, and workmen's compensation, she found not only that these were unavailable but that no organized and well-directed demand existed for them. Instead, she was referred to public health nursing courses. It is not surprising that many an occupational health nurse concluded that additional preparation for her specialty was superfluous.

Orientation and ongoing inservice education for nurses in industry also have suffered from the circumstance of isolation. The nurse who works alone or with a small staff has no one to orient her, and ongoing inservice education programs are not feasible unless a group of nurses take part.

Isolation is not the only obstacle to dynamic ongoing inservice training. In the large industries, the occupational health nurse is a member of a staff that may include as many as 60 other nurses. In these the full-time medical directors provide the guidance. The creation of positions at the level of nursing service director, supervisor, or head nurse has been slow. Although some occupational health nurses have had these titles, few have had both the status 


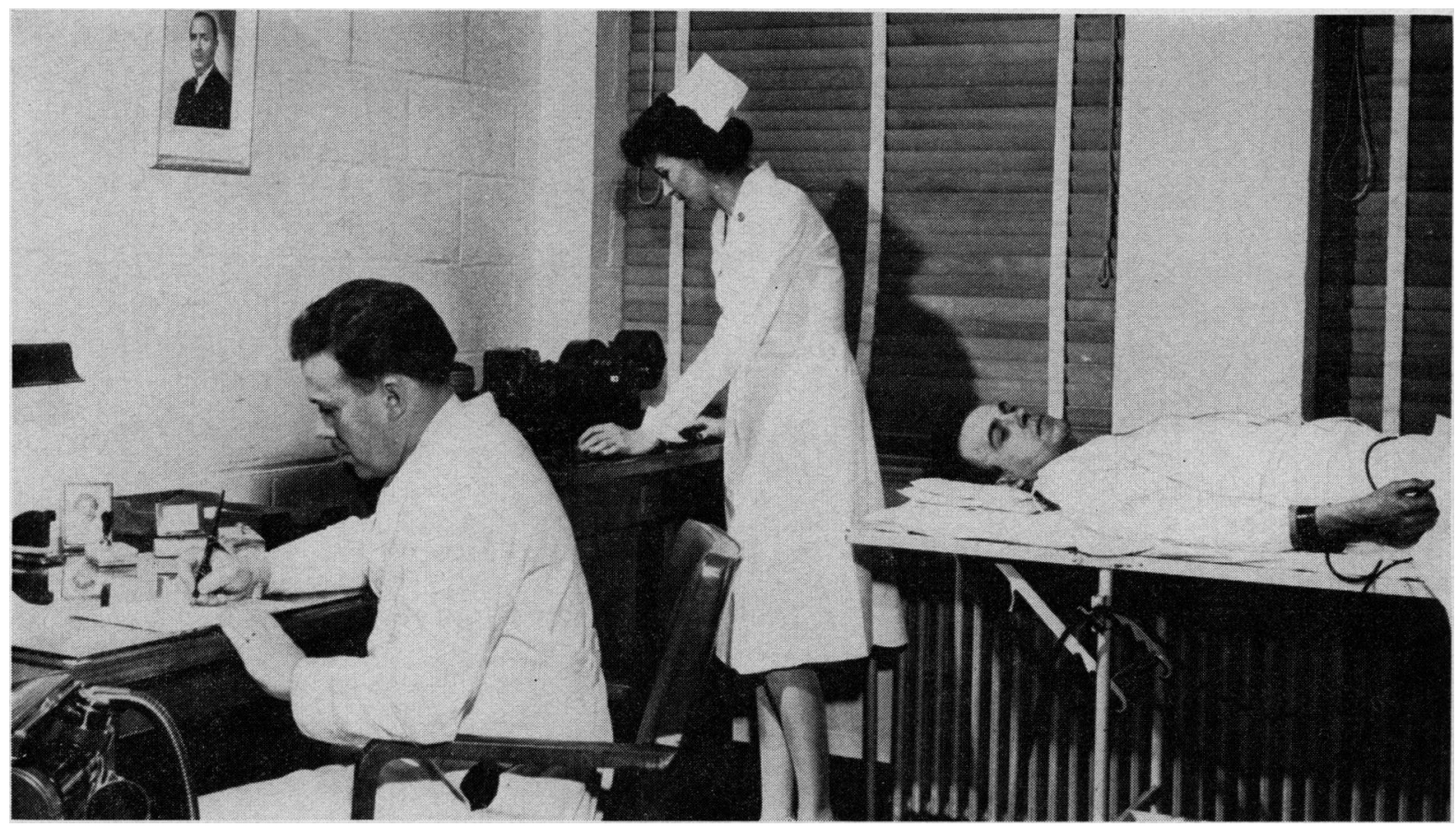

and the authority to create effective occupational health nursing programs, including inservice training.

Too many large programs have been carried on as if they were small programs, with the physician trying to provide nursing supervision in addition to providing entire administration of the program. Long ago it was recognized as a basic principle of health service administration that an essential qualification for the supervisor is professional orientation similar to that of his subordinates. One wonders why busy medical administrators of occupational health programs, unlike their counterparts in hospital clinics and health departments, have failed to delegate responsibility to a chief nurse or nurse supervisor.

Here again a word of tribute should be given to the few who have been different. Some medical directors and industrial management personnel not only have established occupational health nurse supervisory and administrative positions but filled them with competent nurses and established an administrative framework which enabled the nurse in the leadership position to create the nursing aspects of the program and supervise the nurses carrying it on.

In 1914 it was recognized that industrial nursing was a demanding, responsible position for a nurse. It was early recognized that preparation beyond that possible in a hospital school of nursing was necessary, but such training has never been available to any significant degree. The report of the 1963 evaluation conference (8) states that of the 5,178 nurses who had traineeships for full-time study only 12 were employed in industry during the years 1958-63. Of the 10,184 nurses who had short-term traineeship, only 42 were from industry, and 35 of these attended the one course planned for occupational health nurse supervisors. Until preparation for occupational health nursing is available, nurses will have to learn by trial and error.

The potential of occupational health nursing will not be achieved until education at the baccalaureate and graduate levels, supplemented by inservice training, is wanted by occupational health nurses and their employers. Preparation must be available to nurses before they take a position in occupational health and after they do so. "Knowledge and skills of professional personnel cannot be once learned. They must be renewed continuously to keep pace with the rush of demands and new knowledge in the space age" (8).

It is estimated that as of January 1, 1964, there were more than 17,000 occupational health 
nurses in the United States and that by 1970 an additional 5,000 nurses will be needed to maintain the present ratio of nurses to workers in light of the growth rate of the labor force. This estimate does not allow for attrition, which can be predicted to be about 50 percent in the next decade, since those presently employed are largely in the age group 35 years and older. Nor does this provide staffing of new programs for workers in smaller industries.

In the future the supply of adequately prepared occupational health nurses will depend on provision of educational and training opportunities in several areas. While all are essential, first priority should be given to the preparation of nurses for consultation. Of approximately 70 occupational health nurse consultants now employed in the United States, onehalf are expected to retire within this decade.

Activities of half of all occupational health nurse consultants are concentrated in industries insured by the companies that employ those nurse consultants. Hence, consultation for improvement of nursing service in the whole field of occupational health is in limited supply. The likelihood that preparation will be available will depend in large part on the creation of a demand for occupational health nursing consultation. Of the 17,000 occupational health nurses employed in 1963, it is estimated that only 750 have academic preparation beyond a diploma in nursing, and less than 75 of those have preparation in occupational health per se. It is fair to assume, therefore, that leadership preparation is scarce. Indeed, it is known that two-thirds of the occupational health nurses work where they must be self-directive or able to direct the activities of less-prepared personnel.

The Surgeon General's Consultant Group on
Nursing directed its recommendations "to the areas in which Federal assistance can be of particular and immediate significance in increasing and improving nursing personnel and nursing service" (9). They did not single out occupational health nursing. However, as one looks at the record it is clear that significant application must be made of Federal funds for preparation of occupational health nurses if the potential identified in the Goldmark report (6) is to be fulfilled.

\section{REFERENCES}

(1) McGrath, B.: Fifty years of industrial nursing in the United States. Public Health Nurs 37 : 119-124, March 1945.

(2) Klem, M. C., McKiever, M. F., and Lear, W. J. : Industrial health and medical programs. PHS Publication No. 15. U.S. Government Printing Office, Washington, D.C., 1950.

(\$) Trasko, V. M.: The work of State and local industrial hygiene agencies. Public Health Rep 64: 471-484, Apr. 15, 1949.

(4) Bloomfield, J. J. : Governmental industrial hygiene practice in 1942. Ind Med 12: 491-495 (1943).

(5) Whitlock, O. M., Trasko, V. M., and Kahl, F. R.: Nursing practice in industry. PHS Bull. No. 283. U.S. Government Printing Office, Washington, D.C., 1944.

(6) Committee for the Study of Nursing Education: Nursing and nursing education in the United States. The Macmillan Co., New York, 1923, pp. 149-160.

(7) McKiever, M. F.: Data of occupational health interest on American labor force. U.S. Public Health Service, 1962. Mimeographed.

(8) U.S. Public Health Service: Nurses for leadership: professional nurse traineeship program report of 1963 Evaluation Conference. PHS Publication No. 1098. U.S. Government Printing Office, Washington, D.C., 1964.

(9) U.S. Public Health Service: Toward quality in nursing, needs and goals. PHS Publication No. 922. U.S. Government Printing Office, Washington, D.C., 1963. 